\title{
INFLUENTIAL PARAMETERS DURING PRESSURE RELIEF EXPOSED IN WORKING CHAMBER OF HYDRAULIC CYLINDER PRESS
}

\author{
MILUTIN ŽIVKOVIĆ ${ }^{1 *}$ \\ ${ }^{1}$ High Technical Mechanical School Trstenik, Serbia
}

\begin{abstract}
Relieving volumes, which were under pressure, with all the controls on the distribution and management of oil supply, may lead to the occurrence of the hydraulic impact, which is especially distinct in hydraulic presses. For these reasons, high speed unloading compression volume is the main cause of this phenomenon. This paper provide practical guidance for the design and calculation of important design parameters usually embedded devices - hydraulic command check valves (HCCV) (nominal size, pressure and decompression time) and the possibility of determining performance requirements using, from literature, the expressions and the nomograms.
\end{abstract}

Keywords: press, compression volume, pressure relief, pressure impact

\section{INTRODUCTION}

The tendency of every designer and constructor is design of the device or machine that is functional across all criteria. Therefore, the selection of functional parameters and specific solutions of certain strokes working parts of the machine, special attention is paid to the analysis of dynamic and static stability of the control loop. This paper will analyze the use of hydraulic command check valves (HCCV) that are almost a mandatory component in the hydraulic system press, and good luck with the solutions which required high-speed executable machine parts. The selection of possible solutions affect the following assumptions: technical - technological requirements, the manner and conditions of the system, the option of hydraulic elements, economic justification and others.

\section{CALCULATION OF CHARGING VALVE}

In order to adopt the best solution for branch drive cylinder presses primarily has to be taken into account the following conditions:

\subsection{Determination of the nominal size of the valve}

Working piston surface and the speed of falling determine nominal size of charging valve, whereby the valve is applied to the appropriate charging current calculated intake following the first larger diameter of the intake port. Through the size of the valve was also established nominal size of suction line connecting a calculated current intake should not have the speed of more than $1 \ldots 1.2 \mathrm{~m} / \mathrm{s}$ in the tube [1-3].

\footnotetext{
* Corresponding author, email: milutinzivkovicts@ gmail.com

(C) 2016 Alma Mater Publishing House
} 


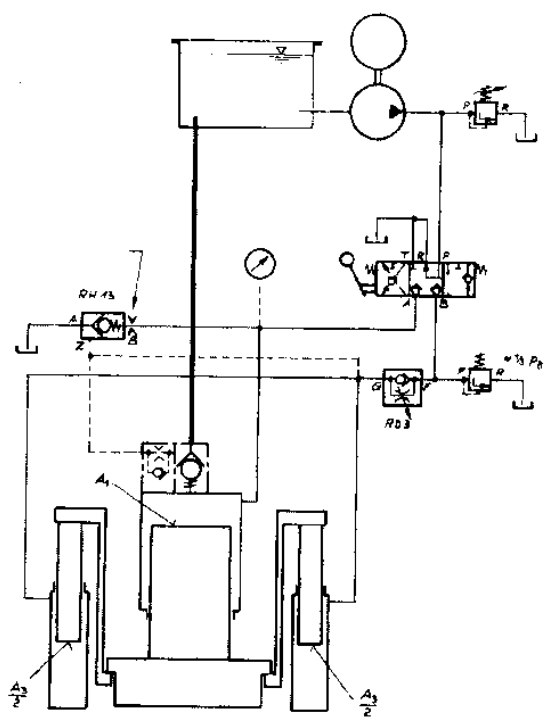

Fig. 1. Hydraulic commanded return valve mounted on the intake line from the drop-down piston.
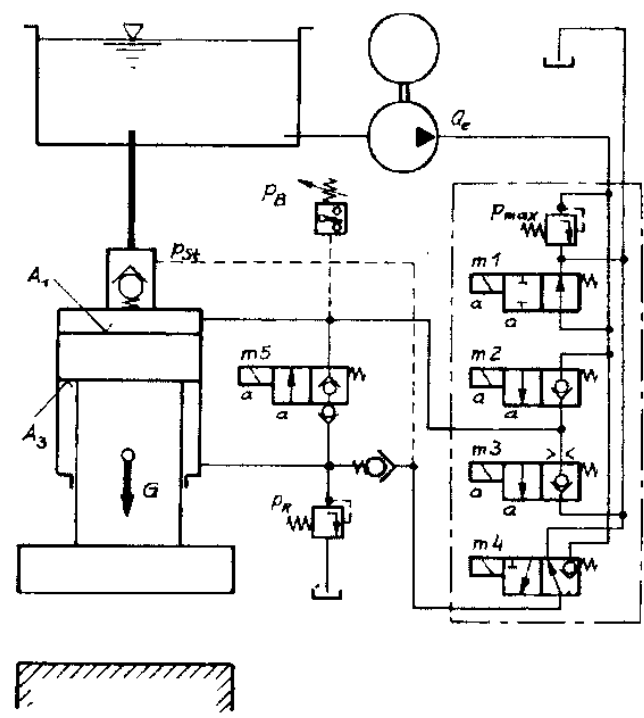

Fig. 2. Hydraulic commanded return valve mounted on two-way cylinder.

With Figure 1 and 2, we see that $[4,5]$ :

$$
\mathrm{G}_{\mathrm{total}}=\mathrm{G}-\mathrm{p}_{\mathrm{otv}} \cdot \mathrm{A}_{1}-\mathrm{R}
$$

Top speed in freefall for the overall weight $\left(\mathrm{G}_{\mathrm{total}}\right)$ :

$$
\vartheta=\sqrt{\left(\mathrm{G}_{\mathrm{uk}} / \mathrm{A}_{3}\right)} / \mathrm{K} \cdot \mathrm{A}_{3}
$$

where: $\mathrm{G}[\mathrm{N}]$ - forces the weight of the piston, the table and tools; $\mathrm{p}_{\mathrm{otv}}[\mathrm{Pa}]-$ valve opening pressure for the charging: $\mathrm{f}\left(\mathrm{R}_{\mathrm{e}}\right)$ according to $\Delta \mathrm{p}-\mathrm{Q}$ valve characteristics; $\mathrm{R}[\mathrm{bar}]$ - constant friction, seals and guides can be estimated or ignored; $\mathrm{A}_{1}\left[\mathrm{~m}^{2}\right]$ - surface during the downward stroke of the suction chamber of the cylinder.

$\mathrm{K}=\sqrt{\Delta \mathrm{p} / \mathrm{Q}} \quad-$ valve factor. 
For a predetermined speed of falling using equation (1) and (2) can, of course, find the size of the manifold or short-contact valve (Figure 1 and 2) [6,7].

\subsection{The ratio of pressure when releasing}

It is common that manufacturers in the catalog documents give the ratio of release, the pilot pressure to the closed side rail. Pressure in the cylinder can be easily expressed for the valves without prior decoupling, equation (3):

$$
\mathrm{p}_{\mathrm{st}}=\mathrm{B} \cdot \mathrm{p}_{\mathrm{z}}+\mathrm{p}_{\mathrm{opr}}
$$

where: $\mathrm{p}_{\mathrm{st}}[\mathrm{Pa}]$ - available control pressure for opening the valve to charge the opposite of closing pressure $\mathrm{p}_{\mathrm{z}}, \mathrm{p}_{z}$ $[\mathrm{Pa}]$ - the pressure in a closed cylinder (operating pressure), B factor of engagement: The surface of the valve / piston surface control valve, $\mathrm{p}_{\mathrm{opr}}[\mathrm{Pa}]$ - pressure value of the valve springs (return oil - and valve springs).

Back pressure was assessed depending on the weight $G$, area ratios $\varphi=A_{1} / A_{3}$, friction $R$ and resistance in the return flow $\Delta \mathrm{p}_{\text {pov }}$ open the charging valve and the corresponding intake port equation (4):

$$
\mathrm{p}_{\mathrm{R}}=\left(\mathrm{G}+\varphi \cdot \Delta \mathrm{p}_{\mathrm{pov}}+\mathrm{R}\right) / \mathrm{A}_{3}
$$

Opening pressure $\left(\mathrm{p}_{\mathrm{z}}\right)$ can be taken approximately equation (5):

$$
\mathrm{pz}=1,2 \cdot \mathrm{G} / \mathrm{B} \cdot \mathrm{A} 3
$$

\subsection{Decompression without impact}

For transitioning from $p_{B}$ to $p_{z}$ it should be predicted "quite a long time" in order to reduce the impact wave in the return pipe. Because of the low internal resistance of the valve to decompress, this size is authoritative for the speed of falling - drawing cylinder piston rod (equations 1 and 2). From the schematically shown solutions can be seen that the management can only be achieved with the use of blends that produce a lot of attenuation and consequently increases the resistance through a valve to decompress and return lines.

For the analytical determination of decompression time will serve us term $(6)[8,9]$ :

$$
t=2 \cdot a \cdot \beta \cdot V \sqrt{p_{\max }-p_{o} \cdot 60}[s]
$$

where: $\quad a \approx 2,24 / \mathrm{d}^{2}$ - calculation factor of shutter $\mathrm{d}(\mathrm{mm})$, through which the decompression is performed. The value of 2.24 was obtained empirically; $\beta=0,6 \cdot 10^{-4}\left[\mathrm{MPa}^{-1}\right]$ - compressibility factor of hydraulic oil; $\mathrm{V}$ [lit] - geometric volume of consumers and pipelines, which initially decompression is under tension $\mathrm{p}_{\max } ; \mathrm{p}_{\max }[\mathrm{MPa}]$ - gauge pressure at the beginning of decompression; $\mathrm{p}_{\mathrm{o}}[\mathrm{MPa}]$ - the pressure in the return pipe, usually taken to be zero.

A simplified value for (d) applies to the area of the viscosity of the working fuid $10 \ldots 200\left[\mathrm{~mm}^{2} / \mathrm{s}\right]$ and the density of $900 \mathrm{~kg} / \mathrm{m}^{3}$ and can be calculated from the characteristics of the shutter from $\Delta \mathrm{p} \approx(\mathrm{a} \cdot \mathrm{Q})^{2}$. If the decompression is not done from $\mathrm{p}_{\max }$ to $\mathrm{p}_{\mathrm{o}}=0$, but to some desired pressure $\mathrm{p}$ [bar] then the difference can be determined ( $\sqrt{\mathrm{p}_{\max }-\mathrm{p}_{\mathrm{o}}}$ ) determined over Klamer's expression (7), [10, 11]:

$$
\left(\sqrt{p_{\max }-p_{o}}-\sqrt{p-p_{o}}\right)
$$

Calculating over factor (a) shows the dependence of, equation (8):

$$
d_{\max } \leq \frac{11,6}{\sqrt[4]{p_{\max }}}(\mathrm{mm})
$$

In Figure 1, the decompression time set by the relationship of pressure and the size of shutter, and the Figure 2 electro commanding, using magnets $\mathrm{m}_{4}$ manifold $2 / 2$, choose time decompression. The nomogram on Figure 3 shows the method of determining the diameter of shutter and Figure 4 the timing decompression [12]. 


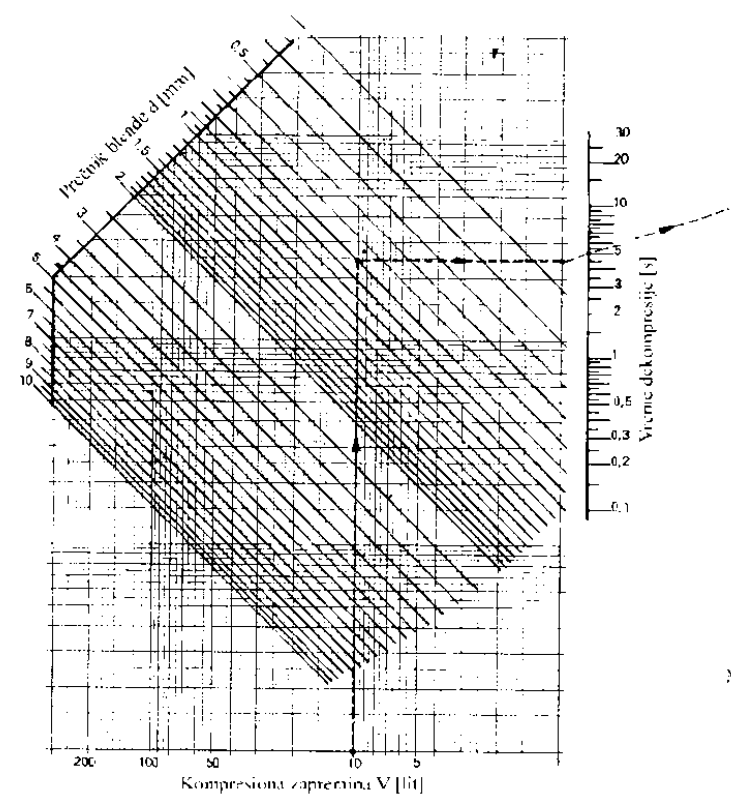

Fig. 3. Determination of decompression time.

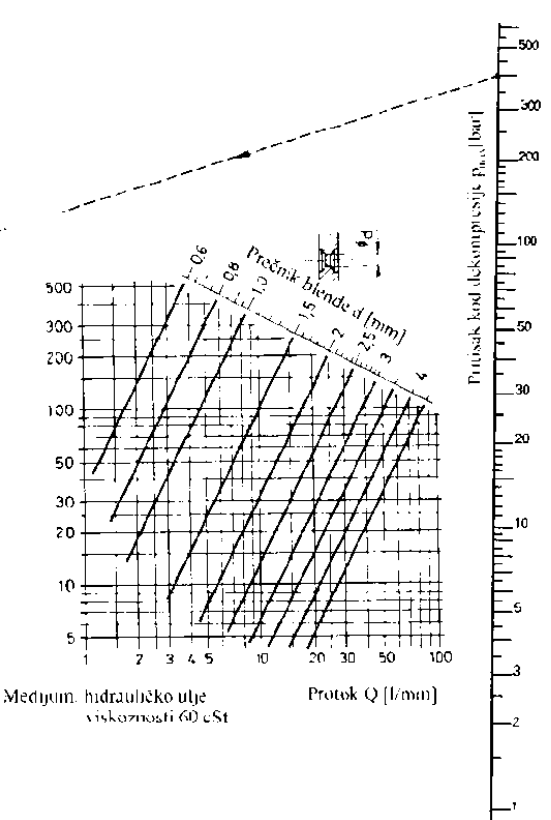

Fig. 4. Determining the size of the shutter.

\section{TYPICAL IMPLIED SOLUTIONS}

When the hydraulic press with a large work force and high frequency cycle solution with HCCV appears as optimal. In Figure 1 and 2 shows some of the characteristic structural solutions of the same, except that the other producers of the same resolve in a similar way [13].

Installation example HCCV, which was done, and in practice, and is hydraulic system solution discharge autoclave coal drying plant in Lazarevac (Vreoci). The same applies to hydraulic manifold installation rapid emptying of the autoclave, and draw the piston rod hydraulic cylinder, which travel from 1700 (mm) achieves 1.2 (s), Figure 6 [4].

This solution enables "streaming" of oil from the chamber side of the piston into the chamber at the rod and the excess oil is at a minimum pressure drop. The proposed solution to the foreign partner, the holder of the coal drying technology in Vreoci (used coal from strip mines), with components (control valve) large nominal width (NO 80) Pos. 2, 3, 4, 5 as well as a safety valve, which PPT - Trstenik in its production program did not have, Figure 6a.
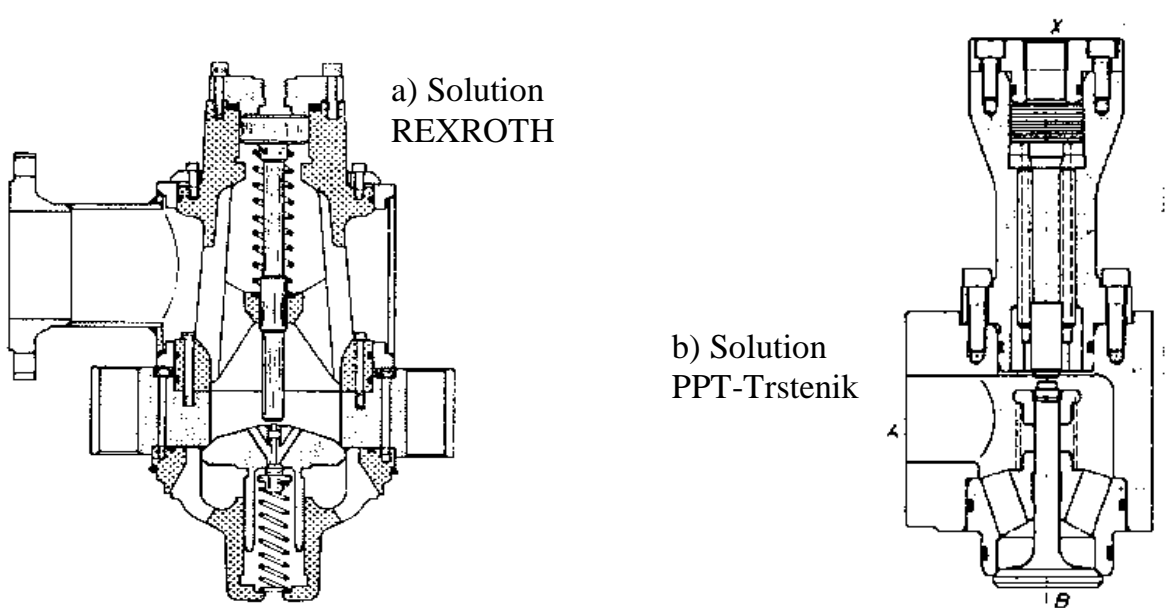

Fig. 5. Some of the structural variants HCCV. 


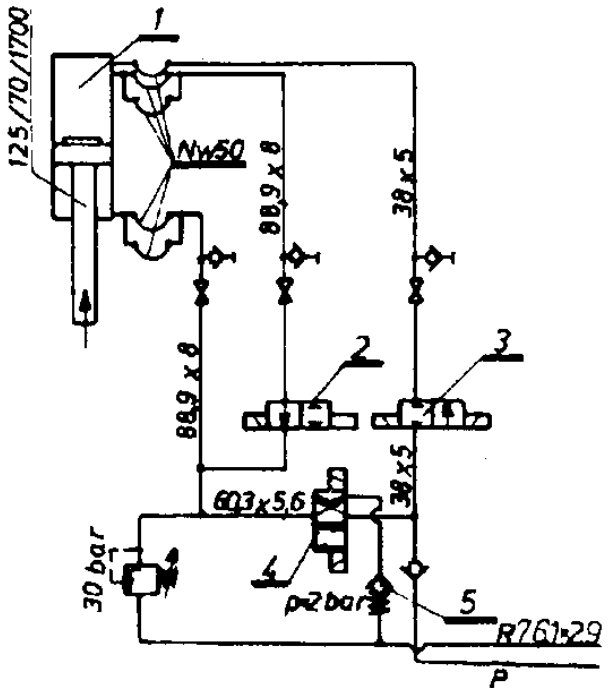

a) Solution of ino-partners

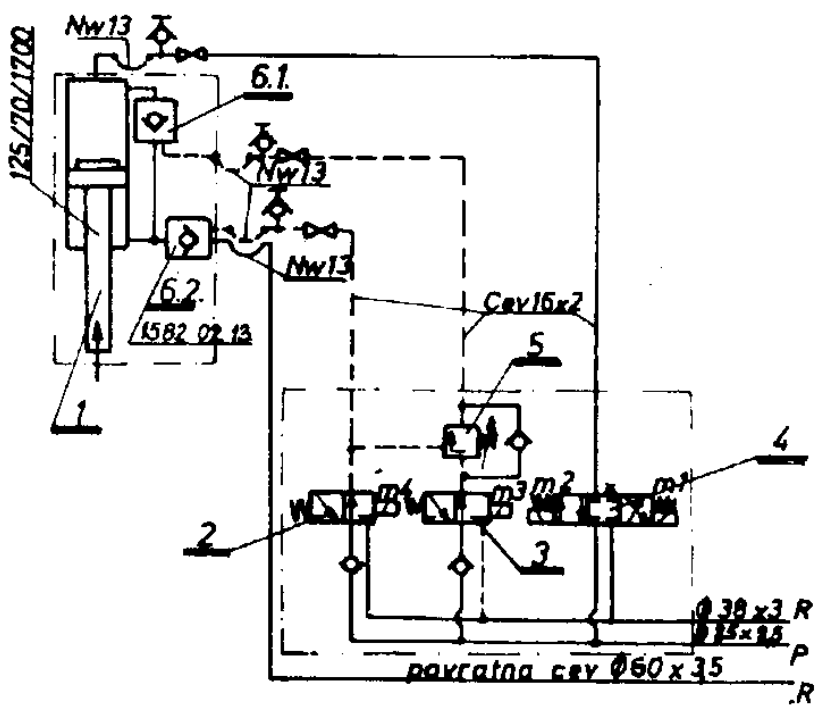

b) Solution of PPT- hydraulics AD

Fig. 6. Solution of hydraulic works, plant installations to quickly open the lid of the autoclave.

The hydraulic system is designed according to the embodiment, given Figure $6 \mathrm{~b}$, with components NO 10 (distributors pos. 2, 3 and 4 and sequenced valve pos. 5 and HCCV nominal size 50). Nominal diameter pipelines have much less flow area, which also can be seen in Figure 6.

\section{CONCLUSION}

When using HCCV it should be taken into account the flows in order to ensure the least possible damping fluid with pressure decompression and time of opening, i.e. needs to be kept above recommendations.

The tendency of all press manufacturers is increasing standardization and unification of operation and management, which provides a faster and more economical construction. To this end, more attention is focused towards developing and manufacturing compact hydraulic block with integrated control valves.

\section{REFERENCES}

[1] Živković, M., Petrović, R., One specific solution in the hydraulic system of coal dryer, Conference HIPET '84, Vrnjačka Banja, Serbia, 1984, p. 295-302.

[2] Beitler, G., Ellbach, N., Determining the decompression of a pressurized volume, Journal O+P, Konstruktions-Nandbuch '79/80, p. 20 - 21.

[3] Živković, M., The selection and installation location of command hydraulic check valves with hydraulic presses, Proceedings HIP 2000, IHP Prva Petoletka AD-Trstenik, Vrnjačka Banja, 20-21. April 2000, p. 141-148. [4] Eskola, T., Handroos, H., Nishiumi, T., Real-time simulated pressure relief valves in physical hydraulic circuit, In American Society of Mechanical Engineers, the Fluid Power and Systems Technology Division, FPST, 2005, p. 171-174.

[5] Gong, Y.J., Zhou, H., Yang, H.Y. Properties of pilot-operated water hydraulic relief valve with different structure parameters, Journal of Zhejiang University (Engineering Science), vol. 40, no. 5, 2006, p. 869-873.

[6] Gong, Y., Simulation and experiments study on water hydraulic pressure relief valve with pilot stage, Journal of Mechanical Engineering, vol. 46, no. 24, 2010 p. 136.

[7] Jia, T.C., Design and performance analysis of digital pressure relief valve of water-based hydraulic. Applied Mechanics and Materials, no. 387, 2013, p. 369-373.

[8] Lin, B.Q., Pressure relief and permeability-increasing technology based on high pressure pulsating hydraulic fracturing and its application, Journal of Mining and Safety Engineering, vol. 28, no. 3, 2011, p. 452-455.

[9] Smith, C.D., Gui, Z., Pressure relief under hydraulic jump stilling basins, In Proceedings - National Conference on Hydraulic Engineering Publ. by ASCE, 1993, p. 1137-1142. 
[10] Tang, H., Yin, Y., Du, G., Experimental study on characteristics of hydraulic motor with a threaded cartridge pressure relief valve, Journal of Central South University (Science and Technology), vol. 45, no. 1, 2014, p. 7783.

[11] Wei, C.F., A study on the pressure relief scope and the stress variation of hydraulic flushing borehole, Journal of Engineering Science and Technology Review, vol. 7, no. 1, 2014, p. 103-108.

[12] Xu, Y., The pressure relief and permeability increase mechanism of crossing-layers directional hydraulic fracturing and its application, Procedia Engineering, no. 26, 2011, p. 1184-1193.

[13] Zhang, Z.M., Simulation and experiment on static characteristic of water hydraulic proportional pressure relief valve, Journal of the China Coal Society, vol. 34, no. 11, 2009, p. 1569-1573. 